\title{
O caso da Lei Mineira das Sacolas Plásticas e a dinâmica dos atores institucionais
}

\section{Luciana Helena Gonçalves}

Anhanguera Educacional, Rod. Régis Bittencourt, 199. Centro. Taboão da Serra-SP (CEP 06768-000).E-mail: lucianahgoncalves@gmail.com.

Resumo. O presente trabalho tem como foco descrever diferentes tipos de regulação sobre a necessidade de substituição das sacolas plásticas presentes em estabelecimentos comerciais, como supermercados, padarias e farmácias, por sacolas biodegradáveis no Município de Belo Horizonte, Capital de Minas Gerais. A escolha deste município mineiro decorre da constatação de uma interessante interação entre diferentes atores institucionais na confrontação do problema que é objeto do presente artigo, ou seja, na implementação de uma política pública, de uma regulação, visando à substituição de sacolas plásticas por sacolas biodegradáveis no cotidiano dos consumidores belo-horizontinos.

Palavras-chave: Sacolas plásticas; Estabelecimentos comerciais; Atores institucionais; Defesa do consumidor; Meio ambiente.

Abstract. The case of Minas Gerais plastic bags legislation and the dynamic of the others institutional actors. This paper aims at describing the different types of regulation on the need for replacing plastic bags with biodegradable bags which are available in establishments, for instance supermarkets, bakeries and pharmacies in the Municipality of Belo Horizonte, capital of Minas Gerais. We have chose this Municipality because we verify that there is an interesting interaction between different institutional actors in the confrontation of the problem which is object of this paper, in other words, in the implementation of a public policy, a regulation, which aims at replacing the plastic bags with biodegradable bags in the day by day of the people from Belo Horizonte.

Keywords: Plastic bags; Establishments; Institutional Actors; Consumer rights; Environment.

\section{Introdução}

O presente trabalho tem como foco descrever diferentes tipos de regulação sobre a necessidade de substituição das sacolas plásticas presentes em estabelecimentos comerciais, como supermercados, padarias e farmácias, por sacolas biodegradáveis no Município de Belo Horizonte, Capital de Minas Gerais. A escolha deste município mineiro decorre da
Recebido:

01/11/2016

Aceito:

$12 / 12 / 2016$

Publicado:

31/12/2016

Acesso Aberto

Artigo completo

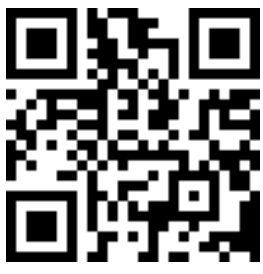

ORCID

(1) 0000-0002-9251-6631

Luciana Helena Gonçalves constatação de uma interessante interação entre diferentes atores institucionais na confrontação do problema que é objeto do presente artigo, ou seja, na implementação de uma política pública, de uma regulação, visando à substituição de sacolas plásticas por sacolas biodegradáveis no cotidiano dos consumidores belo-horizontinos.

Note-se que se considera a definição de regulação na chave da definição de Black (2002, p. 26), a “[...] 
regulação é um processo que envolve a tentativa focada e sustentada de alterar o comportamento dos outros, de acordo com critérios ou padrões definidos, com a intenção de produzir um resultado ou resultados amplamente identificados”.

O objetivo do presente trabalho é o de, por meio da descrição de uma situação ocorrida no Município de Belo Horizonte, verificar a dinâmica que envolve a regulação de um comportamento específico, o dos estabelecimentos comerciais, que oferecem uma sacola como transporte dos seus produtos. Desta forma, a limitação nesta atividade privada gerará uma consequente tensão de interesses, e de valores constitucionais, o que fará com que demais atores institucionais, como 0 Ministério Público e o Poder Judiciário mineiros, criem outras formas de regulação além da que tem como base a Lei mineira das Sacolas Plásticas, partindo de outros valores, a depender do direito fundamental que entendem prevalecer, seja o da defesa do consumidor, por meio do Ministério Público mineiro, seja o do meio ambiente ecologicamente equilibrado, verificando-se, neste último caso, uma intenção de produzir um resultado ecologicamente sustentável por meio da substituição das sacolas plásticas, como se verifica por meio de uma das decisões abordadas, ou seja, a do Tribunal de Justiça de Minas Gerais.

$\mathrm{O}$ primeiro tipo de regulação, ou seja, de limitação à atividade privada dos proprietários de supermercados, padarias e farmácias, é a regulação legislativa tendo como ator institucional o Poder Legislativo Municipal mineiro, que decretou, e o Chefe do Poder Executivo Municipal, que sancionou a Lei Municipal $n^{\circ}$ 9.629/2008, a Lei Mineira das Sacolas Plásticas, que entrou em vigor no dia 27 de fevereiro de 2008.

Esta Lei que norteia este trabalho dispõe que:

Art. $1^{\circ}$ - O uso de saco plástico de lixo e de sacola plástica deverá ser substituído pelo uso de saco de lixo ecológico e de sacola ecológica, nos termos desta Lei.
Art. $2^{\circ}$ - A substituição de uso a que se refere esta Lei acontecerá nos estabelecimentos privados e nos órgãos e entidades do Poder Público sediados no Município.

Art. $3^{\circ}$ - A substituição de uso a que se refere esta Lei terá caráter facultativo pelo prazo de 3 (três) anos, contado a partir da data de publicação desta Lei, e caráter obrigatório a partir de então.

Esta lei foi regulamentada pelo Decreto $\mathrm{n}^{0} 13.446$, de 19 de dezembro de 2008, depois substituído pelo Decreto $\mathrm{n}^{\circ}$ 14.367 de 12 de abril de 2011. (Disponível em: <http://portal6.pbh.gov.br/dom/inicia Edicao.do?method=DetalheArtigo\&pk=105 6045>. Acesso em: 07 nov. 2016).

Em outras palavras, verifica-se que a primeira forma de regulação sobre a substituição das sacolas plásticas convencionais por estabelecimentos comerciais, como supermercados, padarias e drogarias, foi estabelecida por meio de uma Lei Municipal, a Lei mineira das Sacolas Plásticas, que gerou grandes discussões junto à população belohorizontina, como se pode evidenciar por meio da reclamação de uma consumidora, disponível em um site próprio de manifestações online de consumidores, e também por meio da resposta da rede de supermercados, à reclamada:

Todos nós sabemos que em Minas Gerais está proibido a venda de sacolinhas nos supermercados. Ou bem eles fornecem de graça ou simplesmente não colocam as tais sacolinhas para serem vendidas. Acontece que ontem estive no Carrefour Bairro Nova Suiça em Belo Horizonte e lá eles estão vendendo sacolas, aquelas de plástico mesmo, por 0,19 (dezenove centavos) a unidade. Brasileiro é burro mesmo, as pessoas compram, engolem o que eles te empurras. Não é proibido??? Como estão vendendo??? (Reclamante)

Reclamada: Conforme falamos, seguimos a Lei Municipal ${ }^{\circ}$. 9529/08 e seu Decreto $n^{\circ}$. 14.367/11, que nos impossibilita de distribuir sacolas plásticas biodegradáveis gratuitamente em nossas lojas. Permanecemos à 
disposição pelo telefone 0800724 2822, e-mail e Chat disponível no site www.grupocarrefour.com.br, diariamente, das $9 \mathrm{~h} 00$ às $21 \mathrm{~h} 00$. Disponível em: <http://www.reclameaqui.com.br/4431 311/carrefour-loja-fisica/venda-desacolinhas-de-plastico-no-carrefour/> Acesso em: 23/06/2014.

Saliente-se que a reclamação é datada de 31 de janeiro de 2013, quando uma decisão junto ao Tribunal de Justiça de Minas Gerais já havia concluído liminarmente pela opção conferida aos estabelecimentos comerciais de fornecerem a sacola biodegradáveis gratuitamente ou mediante cobrança por sua unidade.

Ao prever o dever de substituição de sacolas plásticas por biodegradáveis pelos proprietários de supermercados, drogarias e padarias, por exemplo, a citada Lei pode ter criado uma forma de limitação na livre iniciativa de estabelecimentos comerciais, escolhendo o tipo de material da sacola que deveria ser utilizada pelos mesmos, meio de transporte com o qual os consumidores carregam os seus produtos, tendo como consequência também a criação de custos adicionais aos estabelecimentos comerciais em virtude da substituição imposta.

Em contrapartida, a Lei Mineira das Sacolas Plásticas também trabalha com valores ambientais, já que se propõe ir em direção a uma concretização de um comportamento mais sustentável, pensandose assim no impacto que as sacolas plásticas causam no meio ambiente, tendo em vista a dificuldade da sua degradação.

Ocorre que, outro valor defendido neste contexto, tendo como contraste a Lei mineira das Sacolas Plásticas, é o da defesa do consumidor, tendo em vista que, se ao empresário caberá a substituição da sacola plástica pela biodegradável, os impactos negativos oriundos de tal troca imposta não recairiam somente sobre o empresário, e é aí que entra o consumidor, também presente no ciclo de vida da sacola plástica, já que a leva consigo ao sair do estabelecimento comercial.
Entramos, então, na segunda forma de regulação da substituição de sacolas plásticas por biodegradáveis: a empreendida pelo Ministério Público mineiro, e assim, rumando-se também ao seu Poder Judiciário. Falamos sobre a atuação do Ministério Público do Estado de Minas Gerais, por meio do seu Procon Estadual, e também do Tribunal de Justiça de Minas Gerais, mediante três decisões, sendo uma de primeiro grau, proferida por uma Juíza singular, e outras duas junto a este Tribunal, por meio de uma interposição de agravo de instrumento com pedido liminar.

Além disso, a participação na implementação da substituição de sacolas plásticas por sacolas biodegradáveis contou com o apoio da Associação Mineira de Supermercados (AMIS), como se depreende das notícias abaixo:

Com o respaldo de uma lei municipal que entrou em vigor dia $1^{\circ}$ de março e proíbe a distribuição de sacolas plásticas que não sejam biodegradáveis, todas as entidades do comércio de $\mathrm{BH}$, o que inclui a Associação Mineira de Supermercados (AMIS), se uniram e conquistaram o apoio do Movimento das Donas de Casas e Consumidores de Minas Gerais (MDC-MG) e da Prefeitura de Belo Horizonte para ir mais além e lançar um campanha em prol da extinção ou redução máxima do uso de sacolas plásticas descartáveis, mesmo que sejam biodegradáveis. (...) Por isso, conclamo a todos os associados da AMIS que possuem lojas em Belo Horizonte a continuarem firmes no compromisso que assumimos com o futuro do planeta. Já solicitei à equipe da AMIS que fique à disposição de todos para detalhar a campanha e dar as dicas e instruções sobre como conduzir este período de transição entre o uso de sacolinha plástica e a adoção da sacola retornável. Ao completar seus 40 anos de fundação, a AMIS dá esse presente para toda a população de Belo Horizonte, que é contribuir para a extinção do uso da sacola plástica. Estamos certos que a campanha será um grande sucesso e que o pionerismo 
da Capital mineira inspirará outras capitais e, quem sabe, todo o País. Conto com você. O planeta agradece." (Revista Gôndola,Palavra do Presidente, pág. 06. Belo Horizonte: Março de 2011, Ano 16, Número 184. 20.500 Exemplares, Distribuição Nacional. Publicação da AMIS). (Da Matta, 2012, p. 4).

“O Futuro Está em Nossas Mãos, Sacola Plástica Nunca Mais”, assim divulgada pela Associação Mineira de Supermercados: "Sacolas plásticas nunca mais. Organizada por todo o comércio varejista e com o apoio da Prefeitura de Belo Horizonte e do Movimento das Donas de Casa e Consumidores de Minas Gerais, uma campanha educativa vai erradicar o uso de sacolinhas em BH. (...) Dia 18 de abril de 2011. Guarde bem esta data em sua memória, pois trata-se de um dia histórico: é nele que Belo Horizonte se transforma na primeira capital brasileira a banir o uso de sacolas plásticas no comércio varejista. E o meio ambiente agradece, afinal, 157 milhões de sacolinhas (como são popularmente conhecidas) deixarão de ser descartadas na natureza em 2011. Este era o consumo de sacolinhas na capital mineira durante um ano. (...) $\mathrm{E}$ não é para menos. A hora da saída no caixa estará totalmente mudada a partir do dia 18 de abril. Os consumidores encontrarão dois tipos de sacolas. As retornáveis (aquelas feitas de TNT, ráfia, tecido de algodão, palha etc.) que estarão sempre disponíveis nos pontos de varejo. A retornável de menor preço para o consumidor será uma oficial da campanha, ao preço máximo de R\$ 1,98 a unidade, vendida a preço de custo pelos varejistas. O consumidor terá liberdade para escolher entre a mais barata (oficial da campanha) e as muitas outras opções de sacolas retornáveis que os varejistas vão colocar à venda. O outro tipo que os consumidores vão encontrar são as sacolas plásticas descartáveis compostáveis (as únicas permitidas por lei). Elas serão vendidas, a preço de custo, ao valor máximo de R\$ 0,19 a unidade. É a primeira vez na história que o consumidor pagará por uma sacola plástica descartável. Vale lembrar que a campanha incentiva o consumidor a trazer de casa sua própria sacola e igualmente a utilizar alternativas como caixas de papelão, carrinhos de feira, etc. A melhor maneira de se estimular a redução do consumo de algo é também a mudança de comportamento é estabelecer valor para o hábito. Ao ter que pagar pela sacola descartável compostável, o consumidor será estimulado a consumir o mínimo necessário ou - como pretende a campanha - abandonar o uso dela, utilizando sempre sua sacola retornável para fazer suas compras (Revista citada, pág. 40). De Belo Horizonte, a campanha rumou para São Paulo, onde, no dia 9 de maio de 2011, o Governador Geraldo Alckimin, o Secretário Estadual do Meio Ambiente, Bruno Covas, e a ação Paulista de Supermercados (APAS) firmaram convênio, para eliminar a distribuição gratuita das sacolas ecológicas no Estado, passando a vendê-las pelo preço de custo, R\$ 0,19 (dezenove centavos), tal como já ocorre em Jundiaí, desde 2010 (16/05/11. In: http://www.portalamis.org.br/site/notici as). (Da Matta, 2012, p. 5).

Passar-se-á, assim, na próxima seção, a abordar mais especificamente a respeito da interação entre diferentes atores institucionais e a Lei mineira das Sacolas Plásticas, ou seja, entre esta legislação municipal e o Ministério Público do Estado de Minas Gerais (MP/MG) e o Poder Judiciário mineiro.

\section{Interação entre MP/MG e a Lei mineira das Sacolas Plásticas}

A decisão administrativa do Ministério Público do Estado de Minas Gerais (Procon Estadual), de julho de 2012, que instaurou o processo administrativo que apresenta como problema a comercialização de sacolas biodegradáveis pelos estabelecimentos comerciais após a obrigação jurídica de substituição das sacolas plásticas convencionais, apresentou como reclamados a Associação Mineira de Supermercados (AMIS) e outros, sendo inserido como reclamante alguns 
consumidores, que se dirigiram ao Procon Estadual contra a cobrança das sacolas biodegradáveis, que se iniciou no mês de abril de 2011, por força da Lei Mineira das Sacolas Plásticas e do Decreto Municipal ${ }^{\circ}$ 14.367, e que antes eram disponibilizadas gratuitamente como meio de transporte de produtos adquiridos, em virtude de alguns dos motivos abaixo mencionados:

Oportunismo; eliminação de custo; obtenção de lucro com a venda superfaturada; cobrança abusiva, pois o consumidor tem de pagar a propaganda da empresa, feita na sacola (Notícia de Fato $\mathrm{n}^{\circ} \quad$ 0024.11.001217 6, Denise Martins Ferreira, 01/03/11,13:04);

Valor abusivo; fragilidade das sacolas; exige que o consumidor preveja, ao sair de casa, se vai comprar algo; inconveniente de misturar, num só ambiente, material de limpeza, verduras, carne...; troca da sacola plástica pelo saco de lixo, que é mais caro e não biodegradável; falta de preocupação da Prefeitura com a coleta seletiva na cidade; ausência de incentivo aos estabelecimentos que buscam a sustentatibilidade (Notícia de Fato $n^{\circ}$ 0024.11.002247-2, Fernanda da Rocha Neves Dumont, 25/04/11, 16:14);

Lesão ao direito do consumidor; o governo municipal não dá tratamento eficaz ao lixo urbano; deve ser decretado o fim das embalagens PET, das embalagens de isopor, das fraldas descartáveis, das embalagens de produtos de limpeza, etc. (Notícia de Fato $\mathrm{n}^{\mathrm{o}}$ 0024.12.000843-8, Luiz Felipe Lehman, 1\%02/12, 12:10);

O consumidor não pode ser obrigado a pagar pela sacola e ainda fazer propaganda da loja (Notícia de Fato $\mathrm{n}^{\circ}$ 0024.12.003182-8, Andrea Cristina de Souza Barbosa, 30/04/12, 17:57);

A venda de sacolas biodegradáveis não vai resolver o problema do mundo (Notícia de Fato $\mathrm{n}^{\circ}$ 0024.12.005272-5, Alisson Augusto, 15/07/12, 17:18). (Da Matta, 2012, p. 1-3).

Desta forma, a decisão administrativa do $\mathrm{MP} / \mathrm{MG}$ retratou que a campanha feita pela Associação Mineira de Supermercados (AMIS) junto aos seus associados inaugurou uma nova prática de mercado: a cobrança, por unidade, das sacolas biodegradáveis, além do tabelamento de seu preço, em R 0,19 (dezenove centavos).

Assim, segundo o MP/MG, essa “[...] nova realidade do mercado - inspirada numa suposta proteção ambiental - teve, como efeito colateral, a formação de cartel e a lesão a outros princípios de ordem econômica, como a livre iniciativa, a livre concorrência e a defesa do consumidor" (Da Matta, 2012, p. 8).

$\mathrm{O}$ MP/MG remeteu-se assim à Lei Antritruste (Brasil, 2011), já que a “[...] livre concorrência se caracteriza, ainda, pela liberdade de escolha para o consumidor" (Santiago, 2008, p. 29), como se pode evidenciar, segundo o MP/MG, também pelo seu artigo 36: “[...] constituem infração da ordem econômica, independentemente de culpa, os atos sob qualquer forma manifestados, que tenham por objeto ou possam produzir os seguintes efeitos, ainda que não sejam alcançados: Ilimitar, falsear ou de qualquer forma prejudicar a livre concorrência ou a livre iniciativa” (Brasil, 2011).

Portanto, de acordo com esta decisão do MP/MG, quer na defesa do livre mercado e da concorrência, quer na proteção do consumidor, há lesão efetiva à ordem econômica, que precisa ser combatida.

Segundo o MP/MG, ocorreria neste caso, ainda, o fenômeno da externalidade, "[...] que segundo Milton Friedman, uma externalidade é o efeito de uma transação para um terceiro que não havia consentido em participar da realização dessa transação” (Da Matta, 2012, p. 12).

O Promotor Da Matta conclui assim, pela admissibilidade das reclamações de consumidores, pois o "[...] custo do das sacolas biodegradáveis (R\$ 0,19 ), segundo divulgado pelo representante dos supermercados, está sendo repassado, desde o início, integralmente, aos compradores dos bens de consumo. Há, na espécie, clara violação à Lei Antitruste” (Da Matta, 2012, p. 11). 
Da Matta recomenda também algumas possíveis soluções que veria como aplicáveis ao problema in casu:

Por que não inovar ? Por que não fidelizar 0 consumidor à sacola retornável, cedendo-lhe o produto ? Identificar a embalagem e rastreá-la. Dar-lhe prêmio (bônus, desconto, pontos para troca em produtos ...), toda vez que retornar com a sacola, no supermercado. Ou com qualquer sacola retornável? Premiá-lo, ainda mais, quando a sacola, já sem utilidade, for devolvida, para ser reciclada. Por quê não utilizar ideia semelhante com as sacolas biodegradáveis, tendo, por critério, a quantidade disponibilizada, na compra? Por quê não cobrar da indústria, a parcela da responsabilidade que lhe cabe, fornecendo embalagens retornáveis e sua recolocação no processo de fabricação de seus produtos? (Da Matta, 2012, p. 13).

O que aparece como interessante, é quando o Promotor menciona também as duas Audiências Públicas realizadas pelo Ministério Público do Estado de Minas Gerais, sendo a segunda com um maior número de convidados, como se evidencia abaixo:

Convidados da primeira Audiência: (i) o Procon Municipal, (ii) o Procon da Assembleia, (iii) a Coordenação do Procon Estadual, (iv) o Centro de Apoio Operacional do Meio Ambiente (MP/MG) (v) a Secretaria Municipal Adjunta de Fiscalização, da Prefeitura de Belo Horizonte, (vi) a Prefeitura de Belo Horizonte, (vii) a Presidência da Comissão de Defesa do Consumidor da Câmara Municipal, (viii) a Presidência da Comissão de Defesa do Consumidor da Assembleia Legislativa, (ix) a Presidência do Fórum dos Procons Municipais, (x) o Movimento das Donas de Casa e (xi) a Associação Mineira dos Supermercados. Na segunda audiência, os convites foram ampliados: (xii) Associação Mineira de Municípios, (xiii) Câmara de Diretores Lojistas (BH), (xiv) Federação do Comércio de Minas, (xv) Instituto Ideais, (xvi) Laboratório de Ciência e Tecnologia de Polímeros, da UFMG, (xvii) Associação Brasileira de Polímeros (ABICON), (xviii) Inmetro e (xix) o consumidor Luiz Felipe Lehman, que, além de reclamar, contribuiu com uma visão geral sobre a matéria (Parte 09). (Da Matta, 2012, p. 15).

Assim, por meio de novas informações técnicas adquiridas nas Audiências Públicas, o Promotor complementou sobre a existência de possível publicidade enganosa no caso, em virtude de duas razões: primeiramente, a grande maioria das sacolas biodegradáveis à venda seria falsificada, e também se constatando que de nada adiantaria o transporte de produtos adquiridos por sacolas biodegradáveis, se não existe uma usina de compostagem no Município de Belo Horizonte, local em que as mesmas deveriam ser descartadas, para que a intenção ecologicamente amigável defendida pela Lei mineira das Sacolas Plásticas surtisse o seu resultado esperado junto ao meio ambiente.

A conclusão MP/MG chega a este raciocínio, por meio do abaixo exposto:

Independentemente da instituição em que trabalho -sou professor do Centro Universitário Newton Paiva -, tenho o dever de levar um pouco do conhecimento que produzimos. Respondendo ao Deputado, há dois meses, resolvemos fazer uma pesquisa no Centro Universitário Newton Paiva, utilizando um equipamento que temos lá que nos mostra a composição do material de que são feitas as sacolas em Belo Horizonte. Fizemos essa pesquisa no comércio em geral de toda Belo Horizonte, em supermercados, farmácias, padarias, "pet shops” e até mesmo em algumas lojas de "shoppings centers". No total, coletamos 135 sacolas. Vendo que muitas delas eram repetidas, analisamos 105. Dessas, concluímos que somente $20 \%$ são constituídas de um material que pode se biodegradar" (Notas Taquigráficas, pág. 26) Depoimento do Professor Luciano Emerich Faria, do Centro Universitário Newton Paiva, ao responder pergunta 
do Deputado Alencar da Silveira Júnior, na audiência pública realizada na ALEMG (03/07/12). (Da Matta, 2012, p. 14).

O equívoco da Lei 9529/2008 pode ser analisado sob vários ângulos, sendo o principal deles o fato de que, tecnicamente, ao propor a substituição das sacolas convencionais por sacolas supostamente biodegradáveis gera, no imaginário da população, a falsa ideia de que as novas embalagens poderiam ser descartadas sem qualquer dano ao meio ambiente, o que não é verdade. As sacolas biodegradáveis só são decompostas caso sejam colocadas em um ambiente de compostagem. Ou seja, para que elas cumpram o seu papel de sacola ecológica é necessário que elas sejam descartadas de forma correta e sejam posteriormente encaminhadas a usinas de compostagem, infraestrutura esta, ainda inexistente em Belo Horizonte e em grande parte do país. Se jogarmos no ambiente, elas serão tão ou mais danosas que qualquer outro material plástico: entupirão bocas de lobo, contribuindo para enchentes nas áreas urbanas, não se degradarão rapidamente e vários outros problemas ambientais (artigo anexo). (Da Matta, 2012, p. 14).

O Promotor Da Matta conclui, assim, que a prática de comercialização de sacolas biodegradáveis por estabelecimentos comerciais, como supermercados, padarias e drogarias, a) violam o "modelo econômico recéminstalado no país”, e também os valores constitucionais da livre iniciativa e da livre concorrência, b) infringem os direitos do consumidor, e o equilíbrio que deve nortear as relações de consumo, ao não reconhecer a sua vulnerabilidade, na medida em que dele é cobrado, ao arrepio da lei, todo o custo empresarial para a introdução, no mercado de consumo, das sacolas biodegradáveis c) ilude o consumidor, ao não informar dado essencial sobre a natureza das sacolas biodegradáveis, ou seja, de que o ganho ambiental por elas trazido depende de outras providências, como a coleta seletiva do produto e a construção de usina para a sua compostagem (Da Matta, 2012, p. 17).

Assim, de acordo com este Promotor, as determinações feitas em sede de decisão de instauração de procedimento administrativo baseiam-se no exercício do seu poder dever de polícia, tendo em vista a necessidade de se proteger os direitos dos consumidores. Note-se, portanto, que a fiscalização do Ministério Público para defender os direitos dos consumidores cria, assim, uma segunda forma de regulação, já que intervém na atividade dos estabelecimentos comerciais deste setor, como é o caso das padarias, supermercados e drogarias, e de uma forma que pode ser vista como ainda mais complexa, pois propõe possíveis soluções e considerações para uma atividade privada específica, além das pensadas pela Lei mineira das Sacolas Plásticas, devendo assim dialogar também com a defesa do consumidor.

Além disso, a decisão administrativa mencionada considerou que a Associação Mineira de Supermercados (AMIS), coordenou e influenciou a conduta de seus associados e dos comerciantes locais para vender sacolas biodegradáveis no preço de R\$ 0,19 (dezenove centavos) a unidade, tipificando a formação de cartel, sendo também repassado ao consumidor o custo de distribuição das sacolas biodegradáveis, assim como o custo da propaganda dos revendedores feitas nas mencionadas sacolas (Da Matta, 2012, p. 20).

\section{Interação entre a Lei mineira das Sacolas Plásticas, a decisão administrativa do MP/MG e o Poder Judiciário mineiro}

Primeiramente, a Associação Mineira de Supermercados (AMIS), tendo em vista a instauração do processo administrativo pelo $\mathrm{MP} / \mathrm{MG}$, que suspendeu a venda de sacolas biodegradáveis e determinou a divulgação da decisão pela impetrante por meio da inserção de nota técnica em seu sítio eletrônico, requereu liminar em mandado de segurança, arguindo a) a ilegitimidade Procon para a 
apuração da prática de Cartel, que é de competência do CADE (Conselho de Defesa Econômica), b) inexistir justo motivo para a instauração de processo administrativo, havendo ofensa ao princípio constitucional da legalidade, à Lei mineira das Sacolas Plásticas e ao princípio da livre iniciativa e do meio ambiente.

Assim, a impetrante requereu que fosse garantida a ela e aos seus associados a comercialização de sacolas biodegradáveis, sendo suspensa a medida cautelar administrativa proferida pela autoridade coatora, o Ministério Público do Estado de Minais Gerais/Procon Estadual.

A juíza de primeiro grau, Moema de Carvalho Balbino Lucas,entendeu que as Promotorias de Justiça de Defesa do Consumidor, no âmbito do Ministério Público, são instrumentos legais de execução da Política Nacional das Relações de Consumo, informada pelo princípio da coibição e repressão de abusos praticados no mercado de consumo, entre outros. (Brasil, 2012).

Desta forma, a instauração de processo administrativo encontrou respaldo no artigo 58 do Código de Defesa do Consumidor (Brasil, 1990), sendo o Ministério Público Estadual competente, inclusive, para aplicar, por medida cautelar, antecedente ou incidente de procedimento administrativo, isolada ou cumulativamente, sanções administrativas como é o caso da multa, apreensão, cassação de registro, proibição de fabricação, imposição de contrapropaganda, suspensão temporária de atividade, cassação de licença ou interdição do estabelecimento ou da atividade, e intervenção administrativa, por exemplo, e previstos nos artigos 55 e 56, do Código de Defesa do Consumidor (Brasil, 2012).

Entendeu-se também que inexistiu a falta de justo motivo para instauração do processo administrativo, já que “[...] à autoridade administrativa cabe a instauração de processo administrativo quando verificar abuso praticado no mercado de consumo, não sendo relevante o fato de a substituição das sacolas plásticas pelas sacolas biodegradáveis ter sido determinado por lei municipal há mais de quatro anos e em vigor há mais de um ano" (Brasil, 2012).

Desta forma, de acordo com a decisão, cabe ao Ministério Público fiscalizar o cumprimento da lei e defender a ordem jurídica, afastando-se a alegação de ofensa ao princípio da legalidade.

Falou-se também que a decisão administrativa do Ministério Público não proibiu a utilização de sacolas biodegradáveis, mas apenas a sua comercialização nos estabelecimentos associados da parte impetrante, tendo em vista a consideração de prática abusiva e lesiva aos consumidores.

A juíza também finalizou, discorrendo que, se existe uma pretensa ofensa ao princípio da livre iniciativa, existe também tal "questionamento no que tange à defesa do consumidor, princípio constitucional também previsto na ordem econômica, previsto no artigo 170, da Constituição Federal de 1988” (Brasil, 2012).

Além disso, a Juíza de primeiro grau decidiu que não caberia ao Poder Judiciário interferir no processo administrativo que nem sequer foi concluído, sendo que a inexistência ou existência do ato lesivo ainda seria verificado ao final do processo, hipótese contrariaà previsão constitucional de impetração de mandado de segurança em casos de lesão de direito líquido e certo do impetrante, nos moldes do artigo $5^{\circ}$, inciso LXIX, da Constituição de 1988 (Brasil, 2012).

Note-se que, um argumento desta decisão que pode ser apontado como decisivo, é o oriundo do juízo de proporcionalidade ponderando-se entre 0 direito fundamental ao meio ambiente ecologicamente equilibrado e o direito fundamental à defesa do consumidor, cuja balança prevaleceu sobre este último, evidenciando-se tal argumentação como um problema no que tange a uma solução mais técnica dada pelo Juiz, não se levando em conta também outras variáveis presentes no caso concreto, como é o caso da compreensão acerca do impacto que a regulação pode causar na atividade empresarial, por exemplo. 
Além disso, a decisão acima mencionada restou reformada pela Desembargadora do Tribunal de Justiça de Minas Gerais, Tereza da Cunha Peixoto, que ponderou a balança entre os dois direitos citados de forma diversa (Brasil, 2013). Tal decisão, oriunda de uma interposição de um Agravo de Instrumento no TJ-MG com pedido liminar constituiu-se em uma decisão favorável à manutenção da venda das sacolas biodegradáveis até a análise final do recurso (disponível em: $<$ https://proconmpmg.wordpress.com/tag/sa colas-plasticas/>. Acesso em 28 jun. 2014).

Assim, a agravante, a Associação Mineira de Supermercados (AMIS), alegou baseada em um fundamento dotado de grande amplitude e por isto, muito utilizado no que tange à concretização dos direitos fundamentais, ou seja, discorrendo que permitir a venda de sacolas plásticas biodegradáveis não ferirá, em momento algum, a dignidade humana. Tampouco a agravante considerou que a venda de sacolas biodegradáveis causará desvantagens veladas a um determinado grupo (no caso, consumidores). Alegou ainda que a desvantagem aos consumidores seria "tênue", tendo em vista os benefícios para a coletividade propostos pela Lei mineira das Sacolas Plásticas (Brasil, 2013).

A Desembargadora Tereza da Cunha Peixoto, entendeu, nesta decisão, que a proibição do uso de sacolas plásticas comuns, propiciando aos supermercados 0 repasse do custo das sacolas biodegradáveis ao consumidor gerou uma maior conscientização da população, que passou a levar a sua sacola retornável ao supermercado, para não ter que arcar com o custo financeiro da compra das sacolas biodegradáveis.

Para elucidar o discorrido pela Desembargadora, notem-se os dados trazidos por uma notícia do Estado de Minas: "De acordo com informações da Associação Mineira de Supermercado (AMIS), Belo Horizonte deixou de despejar no ambiente 160 milhões de unidades de sacolinhas plásticas descartáveis em um ano. Uma pesquisa realizada em abril de 2012 pela AMIS mostra que na capital mineira o uso da sacolinha descartável se transformou em última opção do consumidor. Ainda segundo o levantamento, $95 \%$ da população que realiza compras em supermercados usa a sacola retornável (feitas de TNT, por exemplo), e outros $2 \%$ usam caixas de papelão para transportar os produtos". (Disponível em: <http://www.em.com.br/ app/noticia/especiais/rio-mais-20/noticias/ 2012/06/25/noticias_internas_rio_mais_20, 302273/sacolas-plasticas-entenda-apolemica-a-critica-e-a-defesa.shtml> . Acesso em: 28 jun. 2014).

Desta forma, a Desembargadora também decidiu em favor do meio ambiente ecologicamente equilibrado, discorrendo também que "[...] embora possam existir indícios da formação de cartel em face da alegação do preço fixo cobrado por todos os supermercados, não há, ao menos neste momento, a demonstração efetiva da sua existência” (Brasil, 2013).

Portanto, para a Desembargadora, o direito ao meio ambiente ecologicamente equilibrado impacta até mesmo o princípio da dignidade humana, "[...] uma vez que qualquer ato que o prejudique envolve 0 direito de toda a coletividade” (Brasil, 2013).

A Desembargadora Tereza da Cunha Peixoto também aponta a necessidade da conscientização do indivíduo para um consumo sustentável, sendo que, assim, de acordo com ela, em seu juízo de ponderação, prevalecem-se a proteção do meio ambiente e a vedação ao retrocesso que pode ser concretizado ao ser posto novamente à disposição dos consumidores as sacolas, ainda que biodegradáveis, impedindo a conscientização da população, que já estava se acostumando com isso, ao utilizar uma sacola retornável. Nesta senda, a Desembargadora deferiu, por aquele momento, a manutenção da possibilidade de venda das sacolas biodegradáveis.

Ademais, o julgamento do mérito dessa decisão ocorreu no dia 8 de agosto de 2013. A Oitava Câmara Cível do TJMG considerou que a AMIS não observou o prazo legal de 120 dias para requerer o Mandado de Segurança, conforme 
estabelece a Lei ${ }^{\circ}$ 12.016/2009. De acordo com a relatora do processo, a Desembargadora Teresa Cristina da Cunha, a AMIS teve conhecimento da decisão do Procon-MG em 26 de julho de 2012, sendo que a ação só foi proposta no dia 7 de dezembro de 2012.

Portanto, esta última decisão revogou a liminar concedida, indeferiu a petição inicial do mandado de segurança, e negou o provimento do recurso. $O$ que acabou ocorrendo, por meio desta última decisão do Tribunal de Justiça de Minas Gerais, é que a possibilidade da venda de sacolas biodegradáveis resta, portanto, suspensa (Brasil, 2013).

Note-se a complexidade que envolveu a polêmica da comercialização das sacolas biodegradáveis para os empresários, por meio da notícia abaixo: as polêmicas sacolinhas plásticas voltaram com força total ao comércio de Belo Horizonte. É cada vez mais comum receber o produto com a sacola na hora de pagar a conta no caixa. "Eu acho muito deselegante ter que sair com as compras em caixas de papelão. Eu não compraria em um lugar que não tivesse sacolinhas", defende $\mathrm{o}$ dono da rede de supermercados BH, Pedro Lourenço de Oliveira. As 48 lojas dele na capital chegaram a extinguir o material por quatro meses, quando entrou em vigor a lei municipal que permitia apenas sacolinhas biodegradáveis e compostáveis, em Belo Horizonte. “Choveu reclamação. Aí, nós voltamos a fornecê-las de graça. Nossas vendas subiram 5\% depois disso", comemora o empresário, que gasta $\mathrm{R} \$ 0,08$ por sacola. Ele garante que o próprio supermercado arca com os custos, evitando repassá-los ao consumidor”. (Disponível em: <http://www.otempo. com.br/capa/economia/sacolinhasvoltam-com-força-total-ao-comérciode-bh-1.861558>. Acesso em 28/06/2014).

Até chegar a essa última decisão, várias discussões foram travadas, tendo em vista a profundidade da questão, já que envolve um hábito presente nas relações comerciais de nossa sociedade, como alegou a AMIS ao discorrer que:

a prática adotada por seus associados, pela cobrança das sacolas biodegradáveis, foi "um meio encontrado para coibir a utilização de sacolas plásticas pela sociedade, hábito há muito tempo criado e que se perpetuou ao longo do tempo e de gerações", dentro da "relação PODER PÚBLICO, INICIATIVA PRIVADA E SOCIEDADE, assim considerados os consumidores", objetivando, com isso, banir o uso de sacolas descartáveis, não importa de que natureza, pois se a sociedade criou esse "péssimo hábito", deve "dar sua parcela de contribuição para os fins propostos pela Lei $n^{\circ}$ 9.529, mesmo que alguns ônus lhe sejam impostos” (Da Matta, 2013, p. 3).

\section{Discussão}

Primeiramente, note-se que o Promotor Amauri da Matta fala também sobre um possível constrangimento do consumidor pelo tratamento recebido, tendo em vista ter que carregar as compras nas mãos, caso não comprem as sacolas biodegradáveis, ou até mesmo, com a utilização de outra alternativa, o fornecimento de sacola de papelão, ter esta o risco de estar contaminada por urina ou fezes de ratos (Da Matta, 2013. p. 3). Portanto, saliente-se estar diante de um problema que pode envolver até mesmo questões de saúde pública, como exposto pelo Promotor Amauri da Matta.

Ocorre que, o presente problema não envolve questões em seu caráter abstrato, mas sim a sua melhor solução tendo em vista a sua realidade, que envolve tanto o bolso do consumidor, como do comerciante, e também os impactos gerados no meio ambiente.

Para isto, o Promotor Amauri da Matta discorre a respeito da responsabilização também do estabelecimento comercial para com a conscientização da utilização de sacolas biodegradáveis, observe-se que também não se pode excluir a responsabilização do 
consumidor, pois é o seu comportamento para com a sacola biodegradável que impactará o meio ambiente, e também do Poder Público, tendo em vista a necessidade de serem criadas usinas de compostagem para que a substituição por sacolas plásticas por sacolas biodegradáveis realmente cause uma degradação de seu material em um período de tempo menor.

Ressalve-se a repercussão desta problemática também em âmbito nacional, tendo em vista, por exemplo, o Projeto de Lei $n^{\circ}$ 612/2007, do Deputado Flávio Bezerra, que obriga os estabelecimentos comerciais em todo território nacional a utilizarem sacolas plásticas oxibiodegradáveis - OBP's, as quais terão a finalidade do acondicionamento de produtos e mercadorias em geral, e também o Projeto de Lei do Senado ${ }^{0} 322 / 2011$, que proíbe a utilização, a fabricação, a importação, a comercialização e a distribuição de sacolas plásticas que em sua composição química tenham como base o polietileno, o propileno e o polipropileno. Este último atribui até mesmo ao Instituto Brasileiro do Meio Ambiente e dos Recursos Naturais Renováveis (IBAMA) o exercício de fiscalização da execução desta lei e promoção de campanhas educativas anuais destinadas a conscientizar a população para a necessidade da não utilização das sacolas plásticas.

Ademais, o artigo $3^{\circ}$, do Projeto de Lei do Senado $n^{\circ} 322 / 2011$, dispõe que “[...] resolução do Conselho Nacional do Meio Ambiente (CONAMA) definirá os prazos de retirada gradual das sacolas plásticas do mercado e sua completa substituição por sacolas oxibiodegradáveis ou de outras matérias primas que não ofereçam perigo ao meio ambiente e sejam de fácil degradação”.

Saliente-se que ambos os Projetos de Leis citados preveem a substituição da sacola plástica pela oxibiodegradável, sendo que a justificativa do Projeto de Lei $n^{\circ}$ 612/2007 menciona a experiência da Lei Mineira das Sacolas Plásticas. Contudo, deve-se "separar o joio do trigo". A lei mineira mencionada prevê a substituição de sacolas plásticas por sacolas biodegradáveis. Desta forma, necessário distinguir o termo biodegradável do oxibiodegradável. Enquanto o biodegradável designa uma "decomposição pela ação de organismos vivos, sendo que geralmente pressupõe que os resíduos da decomposição não são tóxicos nem sofrerão bioacumulação, o plástico oxibiodegradável é definido como aquele que recebe um aditivo para acelerar seu processo de degradação, mas não se decompõe em até seis meses. Assim, este não atende as normas técnicas nacionais e internacionais sobre biodegradação. Portanto, não é biodegradável. Este plástico, apenas dividese em milhares de pedacinhos" (Queiroz, 2010).

O mesmo raciocínio é exposto por De Paoli (2012), ao dizer que:

as sacolas plásticas "comuns” são feitas de polietileno, matéria-prima derivada do petróleo ou da cana-de-açúcar, e demoram mais de 100 anos para se decompor. As sacolas oxibiodegradáveis têm uma composição parecida, com uma única diferença: recebem um aditivo que acelera a sua degradação, fazendo com que a sacola se fragmente em pedaços invisíveis a olho nu quando exposta à luz, à umidade e ao ar. O problema é que os minúsculos pedaços parecem não ser consumidos por microrganismos como fungos e bactérias - condição necessária para um material ser biodegradável. Além de os compostos petroquímicos continuarem no ambiente, os aditivos em si podem ser tóxicos. (De Paoli, 2012).

Por esta razão, a Associação Brasileira de Polímeros Biodegradáveis (ABICOM, 2011) já opinou, que a fragmentação não é o mesmo que biodegradação, sendo a primeira o resultado de uma reação química.

Assim, a ABICOM (2011) considera que o termo "oxi-biodegradável" é um termo comercial apelativo muito equivocado, sendo que apenas os termos “biodegradáveis/compostáveis" possuem normas e certificados internacionalmente estabelecidos e reconhecidos que 
eficientemente substanciam as alegações sobre a biodegradação/compostabilidade, tal como ISO 17088. Níveis completos de biodegradação em menos de seis meses devem ser provados, de acordo com o ISO 17088.

A revista Espaço Aberto, da Universidade de São Paulo (USP), também já trouxe a discussão a respeito da eficácia de uma Lei que prevê a substituição das sacolas plásticas, mencionando a experiência do Município de São Paulo (Oliveira, 2012). Desta forma, colocam-se também as posições de Paulo Santos de Almeida, professor no curso de bacharelado em Gestão Ambiental da Escola de Artes, Ciências e Humanidades (EACH) e Marcelo Pereira de Souza, professor de Política e Gestão Ambiental da Faculdade de Filosofia, Ciências e Letras de Ribeirão Preto (FFCLRP), que, mesmo contrários à forma pela qual a política vem sendo conduzida, concordam que a proibição da distribuição de sacolas plásticas é uma medida necessária (Oliveira, 2012). Portanto, saliente-se o discorrido pelos Professores mencionados:

Essa substituição, medida comumente tratada como ecologicamente correta, levanta, no entanto, outras discussões. A vantagem é que algumas sacolas alternativas são reutilizáveis, representando menor volume de lixo produzido do que as plásticas. Muitos tipos das biodegradáveis, porém, contêm substâncias perigosas. Um material desses jogado no aterro acaba causando os mesmos problemas que um não biodegradável. "O mesmo vale para os oxibiodegradáveis”, explica o professor e coordenador do Departamento de Química Fundamental do Instituto de Química (IQ), Luiz Henrique Catalani, especialista em polímeros. "Isso só daria resultado se tivéssemos no País outro tipo de tratamento de resíduos sólidos, como a compostagem." Segundo Catalani, 80\% do lixo sólido brasileiro é levado para aterros sanitários. As sacolas de origem orgânica, como as de amido de milho, essas sim menos prejudiciais, pararam de ser oferecidas em abril por representarem maiores custos aos mercados. Ainda assim, mais do que o foco no combate à poluição residual, a medida busca uma mudança de hábito da população. "Pode ser um início", acredita Almeida. "Contribuirá para a qualidade ambiental como fomentador dos instrumentos previstos pela legislação sobre resíduos, bem como com a conscientização do uso racional de embalagens." É um sentido de educação ambiental que busca chamar a atenção quanto ao uso desnecessário, ou até errado das sacolas. Isso não é, no entanto, conduzido da maneira correta. Para Souza, as medidas isoladas que vêm sendo tomadas não permitirão um processo educativo. "A reciclagem, o reúso, a diminuição de embalagens desnecessárias não são sequer mencionadas”, explica. A efetiva mudança de comportamento será, assim, apenas um efeito colateral incerto (Oliveira, 2012).

Constata-se, portanto, que de nada adianta o Poder Legislativo elaborar leis que proíbam a distribuição de sacolas plásticas convencionais, se não se pensar na existência prévia de um local adequado que será apto para a sua degradação.

Já no caso do Estado de Minas Gerais, já se foram pensadas em outras soluções que não onerem demasiadamente o consumidor, como é o caso do Projeto de Lei $n^{0}$ 1.713/2011, de Divino Pereira (PMN), que propõe alterações na Lei mineira das Sacolas Plásticas, determinando que os estabelecimentos comerciais substituam as sacolas plásticas por similares ecológicos sem preferência de marca ou modelo e as ofereçam gratuitamente ao consumidor,ou também que pensem na distribuição dos custos, como é o caso do Projeto de Lei 1369/10, de Daniel Nepomuceno (PSB), que autoriza o Poder Executivo a conceder subvenção econômica aos estabelecimentos comerciais varejistas que fornecerem sacos e sacolas de material reciclável e biodegradável aos consumidores, por meio de programa a ser gerido e executado pela Secretaria Municipal de Meio Ambiente (Câmara Municipal de Belo Horizonte, 2012). 
Assim, este último texto prevê que os recursos destinados à subvenção serão provenientes de dotações orçamentárias da referida Secretaria, observado o disposto na Lei de Diretrizes Orçamentárias e na Lei Orçamentária Anual, limitando os dispêndios anuais ao montante previsto na dotação orçamentária daquele órgão, em rubrica específica para esse fim. (Câmara Municipal de Belo Horizonte, 2012).

Note-se também a relevância de se incluir na presente discussão a "sondagem de opinião do lojista", feita pelo Sistema Fecomércio Minas/DE, trabalho que buscou traçar um quadro da percepção do empresário do comércio de bens e serviços, com consequentemente impactos na gestão dos negócios, sobre a Lei Mineira das Sacolas Plásticas e o seu decreto regulamentador de 2011.

Isto porque, deve-se entender que a regulação dos estabelecimentos comerciais, por meio da obrigação legal de substituição das sacolas plásticas por biodegradáveis, também deve incluir a consideração de valores econômicos, considerando também os interesses dos empresários, que visam a desempenhar um papel primordial de fornecimento de produtos e de seu material de transporte aos consumidores com base no princípio da eficiência, devendo, assim, tal regulação dialogar não apenas com valores da defesa do consumidor e do meio ambiente ecologicamente equilibrado, mas também com valores econômicos direcionados ao principio da eficiência, por exemplo, tendo em vista a sua interdependência.

Este é o raciocínio empreendido pelos autores Windholz e Hodge (2013, p. 27), ao colocarem, primeiramente, que a regulação social revela duas correntes conflituosas de delimitação pela literatura, sendo concebida, de acordo com a sua finalidade, (a) para corrigir os efeitos prejudicais da atividade econômica (deficiências de mercado); e (b) para atingir determinados resultados socialmente desejados.

Enquanto isso, a regulação econômica é conceituada, de acordo com os seus fins, como "[...] baseada em valores de eficiência e concorrência, e geralmente envolve a correção de falhas ou imperfeições de mercado, que reduzem a eficiência ou concorrência, dentro de um mercado específico, assim como monopólios, informação inadequada ou assimétrica, externalidades ou poder de barganha desigual" (Windolz e Hodge, 2013, p. 26-27).

Ocorre que, após serem feitas tais conceituações de acordo com a finalidade da regulação, note-se que estes autores colocam que a regulação econômica, por exemplo, “[...] não ocorre em umvazio separado de uma discussão sobre valores sociais mais amplos e o tipo de sociedade na qual nós queremos viver: os mercados servem a sociedade, não o contrário" (Windholz e Hodge, 2013, p. 32).

Este raciocínio é o que deve basear a regulação sobre a substituição de sacolas plásticas pelas biodegradáveis por estabelecimentos comerciais, tendo em vista que tal dever atribuído ao empresário não deve ser demasiadamente oneroso, de uma forma que comprometa o exercício da sua própria atividade, da mesma forma que os valores ambientais e de defesa do consumidor devem ser concebidos de uma forma equilibrada e conjunta, sendo a participação por meio de Audiências Públicas um bom exemplo para se acrescer à discussão uma necessária substância técnica, como é o caso da menção da necessidade de existir uma usina de compostagem para que a substituição da sacola plástica pela sacola biodegradável realmente seja efetivada.

Ademais, além de o Código de Defesa do Consumidor (Brasil, 1990) constituir uma regulação mais geral, e não de um setor específico, apresentando tanto a regulação social, como é o caso do princípio do reconhecimento da vulnerabilidade do consumidor no mercado de consumo, como regulação a econômica, tendo em vista, por exemplo, a proteção do interesse econômico do consumidor, que apresenta como um de seus direitos básicos a informação adequada e clara sobre os diferentes produtos e serviços, vedando assim a assimetria da informação. Ocorre que, a proteção do consumidor não pode ser concretizada cegamente, pois a atividade 
empresarial e os consumidores complementam-se e só existem se coexistirem.

Portanto, o que se defende no presente artigo não é a evolução do consumeirismo atuando como simples máquina de reinvindicação de vantagens pontuais (Sundfeld, 2007, p. 10). Como foi exposto acima, em reclamação do consumidor, foi dito que "a venda das sacolas biodegradáveis não resolveria 0 problema do mundo". Ora, esta ação pontual já faria sim uma diferença. Mas para isso, é preciso que se cobre a participação também do Poder Público, como é o caso da necessidade da existência de usinas de compostagem no Município de Belo Horizonte.

Cobra-se do empresário, assim, uma ação optimizada: o fornecimento de sacolas biodegradáveis de forma gratuita. Ocorre que se deve pensar nos custos adicionais assumidos pelo empresário para a implementação da substituição das sacolas, e que por isto, possivelmente, ou aumentará o preço dos produtos de seu estabelecimento, ou cobrará pela unidade da sacola biodegradável. Continuar insistindo na recorrente retórica da onerosidade do consumidor permitirá que este sempre se acomode até mesmo no que tange ao dever do exercício de sua consciência ambiental, já que este poderia se eximir desse suposto dever oneroso, já que a sua ação pontual não "resolve os problemas do mundo".

Desta forma, a "sondagem de opinião do lojista" constitui-se em uma pesquisa quantitativa baseada em amostra do tipo probabilística sendo estratificada pelos principais pontos do comércio varejista das regionais de Belo Horizonte, realizada no período 03 a 06 de maio de 2011, quando foram entrevistados 300 lojistas, e traz assim também o necessário olhar do empresário para com a mudança ocorrida, por meio da Lei mineira das Sacolas Plásticas, falando-se também sobre a opinião que este tem sobre o seu consumidor.

Apareceram respostas interessantes à regulação in casu, como é o caso: a) $68,2 \%$ responderam que a Lei mineira das Sacolas Plásticas garante uma imagem positiva do seu negócio e ao Comércio como um todo no que diz respeito ao consumo consciente;

b) as alternativas oferecidas aos clientes seriam a de I) sacos/embalagens de papel (44\%), II) oferecimento da sacola biodegradável como brinde/sem custo (22,8\%), III) oferecimento de caixas de papelão usadas aos clientes (19\%), e IV) a venda da sacola retornável aos clientes (13,8\%);

c) $79,1 \%$ achou constrangedor que um consumidor saia de um estabelecimento com as mercadorias na mão;

d) o nível de conhecimento da Lei Mineira das Sacolas Plásticas revelou-se como 44\%: muito, 52,5\% pouco, e 3,5\% nada;

e) $65,1 \%$ respondeu que não se interessaria por oferecer a sacola biodegradável mesmo se não fosse obrigada por lei (note-se aqui também o lojista, que se esquiva do exercício de consciência ambiental);

f) houve perguntas também a respeito da possibilidade de a Lei mineira das Sacolas Plásticas ter induzido que empresas se estabelecessem nas cidades limítrofes de Belo Horizonte, sendo que 65,8\% dos empresários responderam que não.

\section{Conclusões}

O presente artigo almejou descrever a situação do Município de Belo Horizonte, que por meio de sua Lei das Sacolas Plásticas trouxe uma nova realidade ao ambiente de consumo belo-horizontino, mudando-se a composição da sacola que transporta os produtos vendidos nos estabelecimentos comerciais.

Ocorre que, tal mudança não é apenas na composição dessa sacola, mas também nos custos arcados pelo empresário, que antes fornecia a sacola de plástico gratuitamente aos seus consumidores.

A situação se complica quando a Associação Mineira de Supermercados (AMIS) sugere o estabelecimento de preço único pelas sacolas biodegradáveis, ou seja, de se ser cobrado 0,19 centavos brasileiros por unidade ao consumidor.

Nesta ótica, uma regulação, limitação na atividade privada do 
empresário, por meio da obrigação legal de este ter que substituir a sacola plástica pela biodegradável passa a incluir novos atores institucionais, o Ministério Público e o Poder Judiciário mineiros, que criam novas formas de regulação além da regulação legislativa já estabelecida, de acordo com o seu próprio entendimento, e que passam a interagir, tanto com a Lei mineira das Sacolas Plásticas, como com os consumidores e empresários afetados por esta primeira regulação.

A judicialização da regulação das sacolas plásticas, uma forma de regulação, e que gerou como uma das suas possíveis consequências a permissão da comercialização das sacolas biodegradáveis, como se evidenciou por meio da primeira decisão, em caráter provisório, do Tribunal de Justiça de Minas Gerais, apresenta como base argumentativa a tensão entre a livre iniciativa da atividade empresarial, sendo esta fundamento do Estado Democrático de Direito e da ordem econômica, o direito fundamental ao meio ambiente ecologicamente equilibrado e o direito fundamental à promoção pelo Estado da Defesa do Consumidor.

Ocorre que, ao se ter valores orientados a distintos fins, oriundos da livre iniciativa e dos direitos fundamentais logo acima mencionados, a judicialização in casu apresenta, em sua argumentação, o “juízo de proporcionalidade” e da ponderação, o que resulta na necessidade de que se prevaleça um, dentre outros valores existentes, muitas vezes não se considerando o problema como um todo, mas sim como interesses fracionados e isolados.

O que se deveria ter em mente é que no mínimo, a argumentação empreendida pelos atores institucionais aqui mencionados, como é o caso da decisão administrativa do MP/MG, as decisões do Poder Judiciário mineiro, e note-se, também a Lei mineira das Sacolas Plásticas, deveriam vir lastreadas com laudos e estudos técnicos de conhecedores da matéria que tragam tanto os requisitos ou bases necessárias prévias para o conhecimento do âmbito atingido (empresarial, do consumidor ou ambiental, por exemplo), como também os impactos da regulação na presente situação, como é o caso das duas Audiências Públicas promovidas pelo Ministério Público do Estado de Minas Gerais, em que se aventou a respeito da necessidade da existência de uma usina de compostagem no Município de Belo Horizonte para a efetiva degradação da sacola biodegradável.

Necessário também seria levar em conta tanto a posição dos consumidores, como também a dos empresários no que tange à avaliação da Lei mineira das Sacolas Plásticas. Tal diálogo demonstra 0 que em teoria já foi falado pelos autores Windholz e Hodge (2013, p. 33) ao discorrerem que, é necessário que se reconheça a "[...] interconectividade e a interdependência dos valores sociais e econômicos; que toda regulação é um juízo de valor sobre o tipo de sociedade na qual nós queremos morar, envolvendo um equilíbrio de valores econômicos e sociais algumas vezes contraditórios”.

Tendo como exemplo a descrição do caso observado no presente trabalho, uma visão de equilíbrio deve ser almejada tendo em vista uma situação complexa em sua essência: almeja-se proteger o meio ambiente ecologicamente equilibrado, existindo ainda assim o fornecimento ao consumidor de uma sacola biodegradável, que na realidade necessita também da existência de uma usina de compostagem para degradá-la, e sendo o consumidor dependente da atividade do empresário que fornece produtos a ele, sendo tal dependência recíproca, e evidenciando-se o consumidor como destinatário final, e por isso, notavelmente responsável para com a destinação que dará à sacolinha, seja ela plástica ou biodegradável, voltando-se à questão de necessidade do exercício de consciência ambiental, tanto do empresário, como do consumidor.

\section{Declaração de conflito de interesses}

A autora declara não haver conflitos de interesses. 


\section{Referências}

ABICOM - Associação Brasileira de Polímeros Biodegradáveis e Compostáveis. Alcançar a sustentabilidade - uma necessidade. s/d. Disponível em: <http://abicomweb.org.br/ imagens/biblioteca/pdf_14f674e2b13d5f_Posici onamento_Sacolas_Plasticas_ABICOM..pdf $>$. Acesso em: 27 jun. 2014.

ABICOM - Associação Brasileira de Polímeros Biodegradáveis e Compostáveis. Plásticos "óxibiodegradáveis”. Parecer novembro 2011. Disponível em: <http://abicomweb.org.br/ imagens/biblioteca/pdf_14f1d5a63bada4_Posici onamento_ABICOM_OXI-

Biodegradaveis_Novembro.pdf $>$. Acesso em: 29 jun. 2014.

Black, J. Critical reflections on regulation. Australian Journal of Legal Philosophy, v. 27, p. 1-35, 2002.

Brasil. Constituição da República Federativa do Brasil de 1988. Disponível em: $<$ http://www.planalto.gov.br/ccivil_03/constitui cao/constituicaocompilado.htm>. Acesso em: 26 out. 2016.

Brasil. Lei $\mathbf{n}^{\circ} \mathbf{8 . 0 7 8}$, de 11 de setembro de 1990. Dispõe sobre a proteção do consumidor e dá outras providências. Disponível em: $<$ http://www.planalto.gov.br/ccivil_03/leis/1807 8.htm>. Acesso em: 31 maio 2014.

Brasil. Câmara Municipal de Belo Horizonte. Pioneira entre as capitais, lei da sacolinha completa um ano. 13/04/2012. Disponível em: $<$ http://www.cmbh.mg.gov.br/chapeu/lei-dasacola-plastica>. Acesso em: 25 maio 2014.

Brasil. Governo do Estado do Mato Grosso do Sul. Parecer técnico UCCA/GFC/IMASUL $\mathrm{n}^{\circ}$ 09/2009. Secretaria do Estado de Meio ambiente, das Cidades, do Planejamento, da Ciência e Tecnologia - Brasil. Campo Grande: SEMAC/IMASUL, 2009.

Brasil. Lei $\mathbf{n}^{\circ} \mathbf{1 2 . 5 2 9}$, de 30 de novembro de 2011. Estrutura o Sistema Brasileiro de Defesa da Concorrência; dispõe sobre a prevenção e repressão às infrações contra a ordem econômica; altera a Lei $n^{0} 8.137$, de 27 de dezembro de 1990, o Decreto-Lei ${ }^{\circ} 3.689$, de 3 de outubro de 1941 - Código de Processo Penal, e a Lei $n^{\circ} 7.347$, de 24 de julho de 1985; revoga dispositivos da Lei $\mathrm{n}^{\circ}$ 8.884, de 11 de junho de 1994, e a Lei no 9.781, de 19 de janeiro de 1999; e dá outras providências. Disponível em: <http://www.planalto.gov.br/ccivil_03/_ato2011 -2014/2011/Lei/L12529.htm>. Acesso em: 28 jun. 2014.
Brasil. Processo no 002412133701-8. Mandado de Segurança. Impetrante: AMIS: Associação Mineira de Supermercados. Autoridade Coatora: Promotor de Justiça da $14^{\mathrm{a}}$ Promotoria de Justiça de Defesa do Consumidor de Belo Horizonte - Estado de Minas Gerais. $3^{\text {a }}$ Vara de Fazenda Pública e Autarquias. Julgado por: Moema de Carvalho Balbino Lucas. Belo Horizonte. Julgado em: 18/12/2012.

Brasil. Agravo de Instrumento $\mathbf{n}^{\mathbf{0}}$ 1.0024.12.133701-8/001. Agravante: AMIS (Associação Mineira de Supermercados). Agravado: Ministério Público do Estado de Minas Gerais. $8^{a}$ Câmara Cível. Julgado por: Desa. Relatora Teresa Cristina da Cunha Peixoto. Julgado em: 11/01/2013.

Brasil. Agravo de Instrumento $\mathbf{n}^{\mathbf{0}}$ 1.0024.12.133701-8/001. Comarca de Belo Horizonte. Agravante(s): AMIS ASSOC MINEIRA SUPERMERCADOS AGRAVADO: MINISTÉRIO PÚBLICO DO ESTADO DE MINAS GERAIS. 8 ${ }^{\text {a }}$ CÂMARA CÍVEL do Tribunal de Justiça do Estado de Minas Gerais. Relatora: Desa. Teresa Cristina da Cunha Peixoto. Julgado em: 08/08/2013.

Da Matta, A. A. Ministério Público do Estado de Minas Gerais. Procon Estadual. 26/07/2012. Instauração de Processo Administrativo. Decisão Administrativa Cautelar. Reclamantes: Denise Martins Ferreira e outros. Reclamados: Associação Mineira de Supermercados e outros.

Da Matta, A. A. Mandado de Segurança: 0024.12.133.701-8. $3^{\text {a }}$ Informações. $3^{\text {a }}$ Vara de Fazenda Pública Estadual. Agravante: AMIS (Associação Mineira de Supermercados). Agravado: Ministério Público do Estado de Minas. Problema: cobrança de sacolas. 14/02/2013.

De Paoli, M.-A. Pergunte aos pesquisadores: qual a diferença entre as sacolas plásticas oxibiodegradáveis e as comuns? (José João Lelis Leal de Souza, via e-mail). Pesquisa Fapesp, 2012. Disponível em: $<$ http://revistapesquisa.fapesp.br/2012/02/18/per gunte-aos-pesquisadores-4/>. Acesso em: 28 jun. 2014.

Fecomercio Minas. A Lei 9529/08 e seus impactos no comércio varejista. Fecomercio Minas. Sesc Minas. Senac Minas. Belo Horizonte - Maio/2011. Disponível em: <http://www.fecomerciomg.org.br/pdfs/2011_so ndagem_ol_sacolas.pdf $>$. Acesso em: 27 jun. 2014.

Oliveira, J. V. O fim das sacolas plásticas. Revista Espaço Aberto, edição 139, junho/2012. Disponível em: 
$<$ http://www.usp.br/espacoaberto/?materia=o-

fim-das-sacolas-plasticas>. Acesso em: 29/06/2014.

Queiroz, T. Conceitos: biodegradável e oxibiodegradável. 2010. Disponível em: $<$ http://www.recicloteca.org.br/consumo/conceit os-biodegradavel-e-oxibiodegradavel/>. Acesso em: 29 jun. 2014.

Santiago, L. S. Direito da concorrência. Salvador: Juspodium, 2008.

Sundfeld, C. A. Meu depoimento e avaliação sobre a Lei Geral de Telecomunicações. Revista de Direito de Informática e Telecomunicações, Belo Horizonte, ano 2, n. 2, 2007.

Sundfeld, C. A.; Rosilho, A. Direito e Políticas Públicas: dois mundos? In: Sundfeld, C. A.; Rosilho, A. (Org.). Direito da regulação e políticas públicas. São Paulo: Malheiros, 2014.

Windholz, E.; Hodge, G. A. Conceituando regulação social e econômica: implicações para agentes reguladores e para atividade regulatória atual. Revista de Direito Administrativo, v. 264, $\quad$ p. 13-56, 2013. http://dx.doi.org/10.12660/rda.v264.2013.14076

Informação da Licença: Este é um artigo Open Access distribuído sob os termos da Licença Creative Commons Attribution, que permite uso irrestrito, distribuição e reprodução em qualquer meio, desde que a obra original seja devidamente citada. 